\title{
No news is (not necessarily) good news: Impact of preliminary results for BRCA1 mutation searches
}

Alison Bish, $P h D^{1}$, Stephen Sutton, PhD' $D^{2}$ Christine Jacobs, BSc, DPSN, RGN ${ }^{3}$, Sara Levene, BSc, MSc ${ }^{3}$, Amanda Ramirez, MD, FRCPsych ${ }^{1}$, and Shirley Hodgson, MD, DM, FRCP

\begin{abstract}
Purpose: Many women who have had breast or ovarian cancer who are undergoing tests for the presence of germline mutations in the BRCA1/2 genes will receive a result that is inconclusive. As this continuing uncertainty may have a detrimental effect on their psychological well-being and it is possible that such results will be misinterpreted as indicating that no mutation is present, studying their effect is important. Methods: Sixty-one women undergoing such tests completed questionnaires 2 weeks after their blood was taken and at 1 week and 6 months after receiving a preliminary "inconclusive" result, i.e., indicating that two thirds of the BRCA1 gene had been tested and no mutation had been found so far. Results: Perceived likelihood of having a mutation and perceptions of cancer risk significantly decreased after receipt of the interim result. There were no changes in levels of psychological distress and worry about cancer, in intentions to have mammograms, to carry out breast self-examination, or to have prophylactic surgery. Conclusions: The continuing uncertainty does not seem to have increased distress; however, it is possible that the inconclusive result is being interpreted as a "good news" result, in view of the fact that perceptions of risk decrease after receipt of the result. Genet Med 2002:4(5):353-358.
\end{abstract}

Key Words: BRCA1 results, breast and ovarian cancer genetics, affected women, psychological distress, risk perceptions

The population risk of developing breast cancer in the UK is 1 in 12 , and the risk of ovarian cancer is 1 in 100 . A small proportion (approximately 5\%-10\%) of women who develop breast and ovarian cancers have an inherited susceptibility to these cancers. ${ }^{1,2}$ To date, two breast and ovarian cancer predisposing genes have been identified-BRCA $1^{3-5}$ and $B R C A 2 .{ }^{6}$ It is possible to detect mutations in these genes in a small number of individuals who have a strong family history of breast or ovarian cancer. Before an unaffected individual can be tested to determine whether or not they have inherited a susceptibility to these cancers, it is first necessary to define the mutation in the family. This involves taking a blood sample from a member of the family who has had breast or ovarian cancer and where there is a high chance of a genetic mutation. The BRCA1 and $B R C A 2$ genes are then analyzed for a mutation. Women undergoing such "mutation search" tests are the focus of the current study. If a mutation is found, a "predictive test" will then be available for close relatives who have not had these types of cancer. Women who have inherited a mutation in the BRCA1 or $B R C A 2$ gene have approximately $80 \%$ risk of developing

$\overline{\text { From }{ }^{1} \text { Cancer Research UK London Psychosocial Oncology Group, St. Thomas's Hospital, }}$ London, England; ${ }^{2}$ Institute of Public Health, University of Cambridge, Cambridge, England; ${ }^{3}$ Department of Clinical Genetics, Guy's Hospital, London, England.

Alison Bish, PhD, Cancer Research UK London Psychosocial Oncology Group, St. Thomas's Hospital, Lambeth Palace Road, London SE1 7EH.

Received: March 1, 2002.

Accepted: April 4, 2002.

DOI: 10.1097/01.GIM.0000029038.64082.6A breast cancer over their lifetime, particularly at a young age, and $40 \%-60 \%$ lifetime risk of ovarian cancer. ${ }^{5}$

The psychological effect on the first individuals in a family to be tested has tended to be relatively underrepresented in the literature, with research mainly focusing on the effects of predictive testing (which would only occur once a mutation has been found). Affected women undergoing a mutation search test carry a potentially substantial stress burden. On an individual level they face the possibility that the test may show that they are at risk of developing a further cancer. In addition, family members are relying on these women to be the first to be tested and then to pass information to the rest of the family. Broadstock et al. ${ }^{7}$ examined levels of psychological distress among unaffected relatives awaiting results of mutation search testing up to 12 months after the blood test was taken. They found that anxiety in fact decreased initially but then increased as the waiting for a result continued. It is important to find out how the women actually having these tests react to this process. In the past, women undergoing mutation searches have been left without any feedback. In the current study it was decided to offer an interim "result" in response to the need of the women attending the clinic for some contact after having given blood and to keep them informed. This practice is common among genetics centers within the UK because of the extremely long time it takes for results to be achieved from mutation searching. It reassures patients that progress is being made with their test and provides an opportunity to review matters with the family.

Reduction of uncertainty is thought to be one of the major psychological benefits of genetic testing, ${ }^{8}$ although uncertainty about developing breast cancer cannot be eliminated even with 
predictive testing as population risk remains and the gene does not have $100 \%$ penetrance. The current study is concerned with examining the psychological impact of an inconclusive result where a partial genetic screen of the $B R C A 1$ gene has been carried out, leaving a considerable residual risk that a mutation is still present. With such results the uncertainty has not been taken away. This may be stressful; for example, a study of Ashkenazi women ${ }^{9}$ found that affected women receiving an inconclusive result reported an increase in intrusive ideation. Friedman et al. ${ }^{10}$ studied the psychological impact of negative or uninformative 185delAG results in Ashkenazi women (with or without a family history of cancer and therefore at differing levels of risk). They found minimal psychological distress overall (although higher levels in the higher risk women), but cancer-specific distress decreased 1 month after the result had been received. It is possible, therefore, that any psychological distress is actually caused by "not knowing" and that any result at all is beneficial. ${ }^{11}$ Indeed, another study of affected women undergoing $B R C A 1$ mutation analysis ${ }^{12}$ found that general anxiety and intrusive thoughts decreased for those women testing "negative" for BRCA1.

While these findings are of interest, it is also important to look at risk perceptions. It is possible that distress may be minimal but risk perceptions may be high and also be affected by the test result. While a positive mutation search finding is conclusive, if no mutation is found this does not indicate that there is no mutation in the family, as an as yet unidentified mutation may be causing the cancer. This type of result is complex and may be difficult for patients to understand. It is possible that the inconclusive result may in fact be seen as a true-negative result. It is important to assess how the recipients perceive results as the result can have an impact on an individual's future behavior. Research has found that it is possible that if people have a negative test result (or perceive that they have), then they may fail to attend for surveillance and be breast-aware..$^{13}$ In addition, risk perceptions may change, with women believing that they are at less risk after receiving the result. A consideration of perceived risk is included in the present study.

The current study is prospective, which enables preexisting psychological state to be taken into account in order to more readily assess the impact of results. In addition, specific measures of psychological distress are used, which is important as general distress may not change but specific cancer worries or perceptions of risk may be affected by test results. It is important to explore the impact the receipt of the preliminary result has in order to anticipate and deal with women's reactions in the clinical setting. The current study aims to examine how the continuing uncertainty affects mood (including perceptions of risk) and reported behavior.

\section{METHOD}

\section{Participants}

This study forms part of a larger longitudinal study of the effects of genetic counseling ${ }^{14}$ for which ethical approval was given. Informed consent to participate in the research was obtained from women undergoing mutation search testing at
Guy's Hospital, London. Women completed a questionnaire 2 weeks after their test. They had all had breast or ovarian cancer and had at least a $10 \%$ chance of carrying a mutation in BRCA1 or BRCA2. They were from different families. Seventy-one women were approached, and 63 completed a questionnaire ( $89 \%$ response rate). Two of these women were subsequently found to be carrying a mutation and were therefore excluded from the current study, which is concerned with examining the psychological effect of an inconclusive result.

\section{Genetic counseling}

Women with a family history of breast/ovarian cancer who attended the family cancer clinic were seen either by a doctor (a consultant clinical geneticist or a specialist registrar in genetics) or a genetic counselor (graduate nurses or science graduates with training in genetic counseling) for nondirective counseling. The sessions took between 45 minutes and one and a half hours. Prior to attending the clinic women completed a family history sheet detailing the number of other cases of cancer in their family, the type of cancer, the relationship of the person to the woman, the age at diagnosis, and death (if applicable). During the consultation a more detailed family history was taken. The basis of genetic inheritance was explained to women, and the limitations and implications of genetic testing were discussed. An estimate of the likelihood that the cancer in the woman's family has a genetic basis was calculated. Blood was taken for analysis if women decided to go ahead with testing. When undergoing this initial counseling and giving blood for testing, women were told that the test was very new (at that time) and that they would be contacted by letter 6 months later, possibly with a preliminary result. Women were told that if no mutation was detected on the two-thirds analysis of $B R C A 1$, the risk to themselves and their family would remain unchanged because this result did not mean that the cancer in their family was not inherited. If a mutation was found, however, there would be implications for the woman herself and her family. It was explained that when the tests were developed, further analysis of their samples would be undertaken and the results would be given to them as they were received.

\section{Procedure}

Six months after having given a blood sample, the 61 women were sent a letter with their "preliminary" inconclusive result, reiterating what had been discussed in the initial counseling session. This letter stated that two thirds of the BRCA1 gene had been searched and that no mutations had been found in the woman's blood sample but that further analysis would be undertaken on the remaining third of the gene, and all of $B R C A 2$, which may identify a mutation. [All women for whom a mutation was found within this period (and who are not included in this study) were contacted and offered an appointment to receive their test results in person.]

A week after this result was sent, the women were sent a questionnaire; 58 returned a completed form (95\%). Six months later, 51 women were sent an additional questionnaire (these women were the first 51 women recruited into the study; 
unfortunately, the study funding period had ended before the remaining 7 women were 6 months past having received their test result); 48 questionnaires were completed (94\%).

The women had a mean age of 52.1 years (SD 11.1, range $32-74)$. Eighty-five percent had children, and $88 \%$ of these women had daughters. Most (77\%) were married or cohabiting with a partner. Just over three quarters $(76 \%)$ were from social classes III (nonmanual, i.e., supervisory or clerical and junior management, administrative, or professional positions) or social class II (intermediate managerial, administrative, or professional positions). More than half (58\%) of the women had some educational qualifications; $42 \%$ of these had a bachelor's or higher degree. Most $(n=56)$ of the women had been affected with breast cancer (92\%), although $4(7 \%)$ had had ovarian cancer and 1 woman had had both. Seventy-three percent had had their cancer in the preceding 5 years. Most women had had some surgery, $42 \%$ a mastectomy, $10 \%$ an oophorectomy, and $43 \%$ a lumpectomy (some women may have had a lumpectomy and then a mastectomy).

\section{Measures}

To assess psychological distress and worry, general and specific measures were used. The Hospital Anxiety and Depression Scale (HADS) ${ }^{15}$ gives separate measures of anxiety and depression assessed over the previous week (range of scores from 0 to 21 ; seven items for anxiety and seven for depression). This scale was completed at each time point in the study. The 28-item version of the General Health Questionnaire (GHQ$28)^{16}$ was used as a general measure of psychological distress (range of scores from 0 to 84 ). For the main analyses this continuous measure was used. However, for descriptive purposes the scale was also scored using the GHQ scoring method and a score of 5 was taken as a cutoff for case/noncase. Cronbach $\alpha$ reliabilities for the three time points for both these measures were greater than 0.81 .

A scale designed to assess specific worry about developing cancer was used (Cancer Worry Scale). ${ }^{17}$ This was adapted to create a scale assessing breast cancer worry and a separate scale to assess worry about developing ovarian cancer. The scales each include six items scored from 1 to 4 with labeled response categories, giving a possible range of scores of $6-24$. The scale includes items to assess how worry about developing cancer has affected mood and activities in the past month, and the frequency and intensity of worry. As the women in this study had already had cancer, they were asked to specify their worry about developing cancer again. These scales were completed at each point in the study. Cronbach $\alpha$ reliabilities for the scale were greater than 0.86 for the three time points.

In addition, two measures of perceived risk were used. One assessed perceptions about breast cancer risk relative to other women of their age [scored on a 5-point Likert-type scale, responses from -2 (much less likely) to 2 (much more likely)]. Some research ${ }^{18}$ suggests that such items lead to the most accurate assessment of women's perceived risk in comparison to, for example, asking women to express their perceived risk in terms of a 1 in ? chance. The second measure assessed perceived likelihood that they carried a mutation [scored on a 5-point Likert-type scale, responses from -2 (extremely unlikely) to 2 (extremely likely)]. Women completed these questions at each of the three time points in the study.

The Impact of Events (IES) Scale ${ }^{19}$ was used to assess the level of event-related psychological distress. It includes two subscales; seven items measure intrusive thoughts and eight measure avoidance. Scores are on a 4-point scale ranging from not at all (0), rarely (1), sometimes (3), often (5). Scores can range from 7 to 35 for intrusion and 8 to 40 for avoidance. For the current study the women were asked to think about their recent test result and indicate how far the statements were true for them during the preceding week. This scale was completed twice, once a week after the result and once 6 months later. Cronbach $\alpha$ reliabilities for the subscales for the two time points were all greater than 0.90 .

The women were also asked about their screening, surgery, and self-examination intentions in order to examine whether there would be any changes in these once they received their result. They were asked to report the likelihood of their having future mammograms and examining their breasts more frequently than they already do, and also to indicate the likelihood that they would have prophylactic mastectomy or prophylactic oophorectomy. These questions were asked at each time point in the study and not tied to any particular test result outcome.

After women had received their test result, they were asked whether they were satisfied with the amount and clarity of the information contained in the results letter and whether they felt they understood what the result meant for their future risk of developing breast and ovarian cancer.

Data were analyzed using SPSS for Windows. Cases with missing data were excluded from individual analyses.

\section{RESULTS}

\section{Reported affect and perceptions of risk before receiving preliminary result}

On the HADS scale, the mean anxiety score was 6.6 (SD 3.6). Forty-two percent of the women scored above 8 , which is the cutoff for possible anxiety disorder, and were therefore showing borderline anxiety. The mean depression score for the group was lower at 3.5 (SD 3.2). Fifteen percent of the women had scores for depression indicating borderline depressive disorder. The mean score for general psychological distress in the current sample, as measured by the GHQ-28, was 21.3 (SD 11.8). Thirty-three percent of women could be classified as "cases" on this scale.

The mean score for worry about developing breast cancer among women in the current study was 11.7 (SD 3.6) and for ovarian cancer it was 8.3 (SD 2.7). Thirty-six percent of women reported that they worry often or almost all the time about developing breast cancer, whereas only $7 \%$ reported these feelings about ovarian cancer. A $t$ test showed that worry about developing ovarian cancer was significantly less than worry about breast cancer $\left(t_{55}=6.6, P<0.0001\right)$. 
Perceptions of risk were high among the women before they had received their test result. The mean score for perceptions of risk of developing breast cancer was 1.4 (SD 0.75), and for likelihood of carrying a mutation it was 0.9 (SD 0.89). Examining these variables in terms of proportions of women endorsing the given options, a third of the women (36\%) thought they were slightly more likely and $52 \%$ thought they were much more likely than other women of their age to develop breast cancer. Regarding the likelihood that they carry a gene mutation, $40 \%$ of the women reported that they were fairly likely to do so and $29 \%$ thought they were extremely likely to have a genetic mutation.

Before receiving their test result, $90 \%$ of women examined their breasts; just over a third (35\%) did so monthly, and 36\% weekly or more frequently. Half of the women reported that they would examine themselves more frequently than they currently do. Nearly all (93\%) reported that they would probably or definitely have mammograms in the future. Intentions to have surgery were fairly high, with $12 \%$ indicating they would probably and $20 \%$ indicating they would definitely have a mastectomy (among those who had not already had one). Twenty percent reported that they would probably and $24 \%$ said they would definitely have an oophorectomy.

\section{Short-term reaction to receiving inconclusive preliminary result}

The women tended to be satisfied with how they had been informed of their preliminary result. Nearly all (91\%) said that they had received about the right amount of information, and $95 \%$ felt that the information was fairly or extremely clear. The majority $(86 \%)$ felt that they probably or definitely understood what the result meant for their future risk of developing breast cancer and $62 \%$ felt they probably or definitely understood the information about their risk of ovarian cancer, although $28 \%$ reported that they probably did not understand this.

Based on their responses to the IES Scale, it would seem that the result did not cause particular distress to the women. Nearly a third (29\%) reported no intrusive thoughts about their test result in the week following receipt of their letter. However, a small minority were reporting thoughts such as sometimes (37\%) or often (5\%) thinking about the result when they did not mean to; sometimes $(7 \%)$ or often $(5 \%)$ having trouble falling asleep because of thoughts about it; and any reminder sometimes (26\%) or often (7\%) bringing back feelings about it. Regarding avoidance of the result, $38 \%$ of women reported that they did not do this at all. However, $16 \%$ sometimes tried not to talk about it, $27 \%$ sometimes tried to forget about it, 30\% sometimes avoided getting upset when they thought of it, and $20 \%$ sometimes stayed away from reminders of it. Mean scores for the subscales were 5.9 (SD 7.5) for intrusion and 7.1 (SD 9.4) for avoidance.

\section{Changes in psychological distress, perceptions of risk, and screening or surgery intentions after receipt of preliminary result}

Repeated-measures analyses of variance (ANOVAs) were carried out to examine whether there were any significant changes in psychological state, perceptions of risk, or screening or surgery intentions from before receiving the preliminary inconclusive result to up to 6 months after. The IES scores were compared from just after the result to 6 months later as no preresult score had been taken. Table 1 shows the mean scores at each time point for each variable and the results of the ANOVAs.

\section{General anxiety and depression and psychological distress}

During the study period there were no changes in levels of general anxiety or depression as measured by HADS. In addition, there were no changes in general psychological distress as measured by the GHQ-28 (Table 1).

\section{Worry about breast cancer and worry about ovarian cancer}

No significant changes were found for levels of worry about breast cancer or about ovarian cancer (Table 1).

\section{Perceived risk of developing breast cancer}

Perceptions of risk of developing breast cancer significantly decreased in the course of the study. Paired $t$ tests showed that the reduction occurred between preresult and immediately afterward $\left(t_{41}=2.35, P<0.05\right)$, with no significant reduction occurring between immediately after the result and 6 months later $\left(t_{41}=0.00\right.$, not significant) (Table 1$)$. In terms of the numbers of women endorsing the given options, the percentage of women believing that their risk was much more than that of other women fell from $52 \%$ to $41 \%$ immediately postresult.

\section{Perceived likelihood of carrying a gene mutation}

Perceptions of the likelihood of carrying a gene mutation significantly decreased over the course of the study. Paired $t$ tests showed that a significant reduction occurred between preresult and immediately afterward $\left(t_{43}=4.23, P<0.001\right)$, and a significant increase in perceptions of likelihood occurred between immediately after the result and 6 months later $\left(t_{43}=\right.$ $-2.39, P<0.05)$. The average perception of the likelihood of carrying a gene mutation was, however, still lower than at preresult, at this 6 months postresult stage $\left(t_{43}=2.71, P<0.05\right)$ (Table 1). In terms of the numbers of women endorsing the given options, the percentage of women believing that their carrying a genetic mutation was extremely likely fell from $31 \%$ to only $11 \%$ immediately after receiving the result (differing percentage from that previously reported due to missing data for this analysis). Six months later, $18 \%$ of women thought it was extremely likely.

\section{Screening and surgery intentions}

No significant changes occurred in intentions to have mammograms or to carry out breast self-examination more frequently, nor were there any changes in intentions to have a mastectomy or oophorectomy, with intentions still remaining fairly high for all variables (Table 1). 
Table 1

Mean scores at each time point for each variable and results of repeated-measures analyses of variance (ANOVAs) examining changes after receipt of inconclusive test result

\begin{tabular}{|c|c|c|c|c|c|}
\hline \multirow[b]{2}{*}{ Measures } & \multirow[b]{2}{*}{ Preresult } & \multirow{2}{*}{$\begin{array}{c}\begin{array}{c}2 \text { weeks } \\
\text { postresult }\end{array} \\
\text { Mean }(\mathrm{SD})\end{array}$} & \multirow{2}{*}{$\begin{array}{c}6 \text { months } \\
\text { postresult }\end{array}$} & \multirow[b]{2}{*}{ ANOVA result } & \multirow{2}{*}{$\begin{array}{l}\text { Time } 1 \text { mean } \\
\text { 95\% CI }\end{array}$} \\
\hline & & & & & \\
\hline HADS anxiety & $6.5(3.66)$ & $6.2(4.41)$ & $6.3(4.59)$ & $F_{2,46}=0.56, \mathrm{~ns}$ & 6.7 \\
\hline HADS depression & $3.5(3.22)$ & $3.3(3.09)$ & $3.5(3.56)$ & $F_{2,45}=0.38, \mathrm{~ns}$ & 3.7 \\
\hline GHQ-28 & $21.3(11.82)$ & $22.3(12.21)$ & $22.5(10.91)$ & $F_{2,45}=0.98, \mathrm{~ns}$ & 20.9 \\
\hline Breast cancer worry & $11.7(3.68)$ & $11.3(3.93)$ & $10.9(3.71)$ & $F_{2,43}=2.59, \mathrm{~ns}$ & 11.8 \\
\hline Ovarian cancer worry & $8.3(2.71)$ & $8.2(2.68)$ & $8.2(2.73)$ & $F_{2,39}=0.26, \mathrm{~ns}$ & 8.5 \\
\hline \multirow[t]{2}{*}{ Risk perceptions } & $1.4(0.74)$ & $1.1(1.05)$ & $1.1(0.90)$ & $F_{2,41}=4.92, P<0.01$ & Time $1: 1.4^{a}$ \\
\hline & & & & & $\begin{array}{l}\text { Time } 2: 1.0 \\
\text { Time } 3: 1.0\end{array}$ \\
\hline \multirow[t]{3}{*}{ Perceived likelihood of mutation } & $0.9(0.89)$ & $0.3(0.97)$ & $0.6(0.91)$ & $F_{2,43}=11.42, P<0.001$ & Time $1: 0.9^{a}$ \\
\hline & & & & & Time $2: 0.3$ \\
\hline & & & & & Time 3:0.6 \\
\hline Intention to have mammograms & $1.7(0.90)$ & $1.7(0.72)$ & $1.7(0.86)$ & $F_{2,40}=0.53, \mathrm{~ns}$ & 1.8 \\
\hline Intention to carry out breast self-examination more frequently & $0.2(1.24)$ & $-0.1(1.23)$ & $-0.3(1.25)$ & $F_{2,41}=2.21, \mathrm{~ns}$ & 0.1 \\
\hline Intention to have prophylactic mastectomy & $-0.2(1.43)$ & $-0.7(1.33)$ & $-0.4(1.40)$ & $F_{2,36}=1.43, \mathrm{~ns}$ & -0.3 \\
\hline Intention to have prophylactic oophorectomy & $-0.3(1.26)$ & $-0.4(1.29)$ & $-0.7(1.44)$ & $F_{2,33}=2.12, \mathrm{~ns}$ & 0.3 \\
\hline Intrusion $^{b}$ & - & $5.9(7.51)$ & $5.8(8.11)$ & $t_{44}=0.34, \mathrm{~ns}$ & 6.1 \\
\hline Avoidance $^{b}$ & - & $7.1(9.42)$ & $7.2(8.94)$ & $t_{44}=1.86, \mathrm{~ns}$ & 7.2 \\
\hline
\end{tabular}

Sample sizes vary due to missing data. $\mathrm{CI}=$ confidence interval.

${ }^{a}$ All three times are given as there were significant differences between the times.

${ }^{b}$ Intrusion and avoidance were measured at two time points only (post test result), hence $t$ test results.

\section{Intrusion and avoidance}

No significant changes occurred between the 1-week assessment of intrusion and avoidance of the test result and the 6-month follow-up (Table 1).

\section{DISCUSSION}

The women in the current study are still in a state of uncertainty regarding whether or not they carry a mutation, and this could be detrimental to their psychological well-being. The levels of preresult borderline anxiety or depression are in fact higher than in some other studies involving women undergoing predictive testing. For example, in a Dutch sample of unaffected women undergoing predictive testing for the presence of BRCA1/2 mutations, it was found that only $26 \%$ scored above 8 on the anxiety scale and only $7 \%$ had scores indicating borderline depression, ${ }^{20}$ compared with $42 \%$ and $15 \%$ in this study. The proportion of GHQ cases was comparable with proportions found in other research of women undergoing genetic counseling. ${ }^{21,22}$ However, although the women are fairly anxious and remain so throughout the course of the study, there is no increase in anxiety or depression following the inconclusive result.

More important, specific worries about developing breast or ovarian cancer did not increase after receipt of the result. In addition, the level of intrusive thoughts and avoidance regarding the test result is fairly low, indicating that the result is not causing women psychological distress. Higher levels of both intrusion and avoidance have been found among other samples. For example, in one study, ${ }^{23}$ mean scores of 9.0 for intrusion and 9.4 for avoidance were reported at 1 to 2 weeks after receiving a predictive test result, compared with means of 5.9 and 7.1 in this study. Although lower levels were found in the general Ashkenazi sample studied by Friedman et al., ${ }^{10}$ it is possible that as all Ashkenazi women were eligible for testing, regardless of personal risk, levels of distress may have been lower than those in an affected group, such as in the present study. It is also possible that the current sample is interpreting their inconclusive result as a potentially negative result and are therefore not particularly distressed by it. In the study of affected women undergoing testing, ${ }^{12}$ intrusive thoughts decreased after they received "negative" $B R C A 1$ results. It is possible that these findings differ from the current study because of the way in which the results were presented to the women, i.e., as negative rather than negative for $B R C A 1$ only but that another gene may be causing the cancer in their family.

It is possible that these women who have already had breast or ovarian cancer and who are undergoing a mutation search for the presence of $B R C A 1 / 2$ mutations may fail to understand the meaning of a preliminary result (even if receiving it does 
not cause them undue distress) and interpret the result as a "good news" result. This may explain the relatively low levels of psychological distress and intrusive thoughts. Perceptions of risk of developing breast cancer in the future significantly decrease after receipt of the letter. In addition, women feel that it is less likely than before that they carry a mutation. While the perceived likelihood rises slightly at 6 months after the result, it still remains significantly less than at preresult. Previous research $^{24}$ has found that psychological distress decreases in noncarriers, and these reductions in perceptions of risk may be indicative of a misinterpretation of the meaning of the inconclusive result. There was no evidence found in the current study that the result is influencing intentions to have screening and surgery. Previous research has shown a reduction in intention to have surveillance among women who test negative for genetic mutations. ${ }^{24}$

The study findings are important in that results are currently being made available in genetics centers around the UK for $B R C A 2$ testing, but like BRCA1 in the current study, negative results for a particular mutation still cannot rule out a genetic susceptibility to breast/ovarian cancer as other genes may exist which have yet to be identified. In addition, it is now possible for women to submit a blood sample to a private company for testing for the two known cancer-predisposing genes. Here too, negative results cannot rule out the presence of mutations. The results of the current study suggest that levels of distress may be relatively low but that efforts should be made to avoid misinterpretation of the results and unrealistic perceptions of risk.

A limitation of the current study is that it was based in only one clinic and involved a relatively small sample of women. The findings therefore need to be replicated in other clinics and with a greater number of patients before firm conclusions may be drawn. It may also have been helpful to have a separate group of women receiving the result in person and a control group who were not given the preliminary result at all, in order to more readily examine whether changes in risk were caused by the result, its method of delivery, or simply the passage of time. Unfortunately, clinical practice did not allow for this study design.

However, despite the limitations, the findings of the current study would suggest that giving inconclusive results for $B R C A 2$ analyses would be unlikely to cause undue distress to women. It remains possible, however, that inconclusive results may be misinterpreted as indicating that no mutation is present in the family.

\section{Acknowledgments}

The authors are grateful to the Cancer Research Campaign for financial support for this study. In addition, they thank all the women who took part in the research; the clinicians who counseled some of the women (Sally Watts, Gillian Scott, Annelise Nehammer, Louise Izatt, Kristen Becker, and Philip Beales); the laboratory personnel who carried out the preliminary DNA analysis (David Ellis, Jill Greenman, Steve Abbs, and Sam McCall); and Henry Potts, who provided statistical advice.

\section{References}

1. Claus EB, Risch N, Thompson WD. Genetic analysis of breast cancer in the cancer and steroid hormone study. Am J Hum Genet 1991;48:232-242.

2. Easton D, Peto J. The contribution of inherited predisposition to cancer incidence. Cancer Surv 1990;9:395-416.

3. Miki Y, Swensen J, Shattuck-Eidens D, Futreal PA, Harshman K, Tavtigian S, Liu Q, Cochran C, Bennett LM, Ding W. A strong candidate for the breast and ovarian cancer susceptibility gene BRCA1. Science 1994;266:66-71.

4. Narod SA, Ford D, Devilee P, Barkardottir RB, Lynch HT, Smith SA, Ponder BA, Weber BL, Garber JE, Birch JM. An evaluation of genetic heterogeneity in 145 breast-ovarian cancer families. Breast Cancer Linkage Consortium. Am J Hum Genet 1995;56:254-264.

5. Easton DF, Ford D, Bishop DT, and the Breast Cancer Linkage Consortium. Breast and ovarian cancer incidence in BRCA1 mutation carriers. Am J Hum Genet 1995; 56:265-271.

6. Wooster R, Bignell G, Lancaster J, Swift S, Seal S, Mangion J, Collins N, Gregory S, Gumbs C, Micklem G. Identification of the breast cancer susceptibility gene BRCA2. Nature 1995;378:789-792.

7. Broadstock M, Michie S, Gray J, Mackay J, Marteau TMM. The psychological consequences of offering mutation searching in the family for those at risk of hereditary breast and ovarian cancer: a pilot study. Psychooncology 2000;9:537-548.

8. DudokdeWit AC, Tibben A, Dujvenvoorden HJ, Frets PG, Zoeteweij MW, Losekoot M, van Haeringen A, Niermeijer MF, Passchier J, and other members of the Rotterdam/Leiden Genetics Workgroup. Psychological distress in applicants for predictive DNA testing for autosomal dominant, heritable, late onset disorders. J Med Genet 1997;34:382-390.

9. Hurley K, Valdimarsdottir H, Brown K, Rispoli J, Stravinski L, McGlynn J, Grant D, Eng C. Intrusive ideation about cancer risk before and after BRCA1/2 mutation testing. [abstract]. Am J Hum Genet 2001;69:224.

10. Friedman LC, Webb JA, Richards S, Lynch GR, Kaplan AL, Brunicardi FC, Plon SE. Psychological impact of receiving negative BRCA1 mutation test results in Ashkenazim. Genet Med 1999;1:74-79.

11. Baum A, Friedman AL, Zakowski SG. Stress and genetic testing for disease risk. Health Psychol 1997;16:8-19.

12. Wood ME, Mullineaux L, Kulchak Rahm A, Fairclough D, Wenzel L. Impact of BRCA1 testing on women with cancer: a pilot study. Genet Test 2000;4:265-272.

13. Lerman C, Narod S, Schulman K, Hughes C, Gomez-Caminero A, Bonney G, Gold K, Trock B, Main D, Lunch J, Fulmore C, Snyder C, Lemon SJ, Conway T, Tonin P, Lenoir $\mathrm{G}$, Lunch H. BRCA1 testing in families with hereditary breast-ovarian cancer. IAMA 1996;275:1885-1892.

14. Bish A, Sutton S, Jacobs C, Levene S, Ramirez A, Hodgson S. Changes in psychological distress after cancer genetic counselling: a comparison of affected and unaffected women. Br J Cancer 2002;86:43-50.

15. Zigmond AS, Snaith RP. The Hospital Anxiety and Depression Scale. Acta Psychiatr Scand 1983;67:361-370.

16. Goldberg D, Williams P. A user's guide to the General Health Questionnaire. Windsor, UK: NFER-Nelson, 1988.

17. Lerman C, Trock B, Rimer BK, Jepson C, Brody D, Boyce A. Psychological side effects of breast cancer screening. Health Psychol 1991;10:259-267.

18. Woloshin S, Schwartz LM, Black WC, Welch G. Women's perceptions of breast cancer risk: how you ask matters. Med Decis Making 1999;19:221-229.

19. Horowitz M, Wilner N, Alvarez W. Impact of Event Scale: a measure of subjective stress. Psychosom Med 1979;41:209-218.

20. Lodder LN, Frets PG, Trijsburg RW, Meijers-Heijboer EJ, Klijn JGM, Duivenvoorden HJ, Tibben A, Wagener A, van der Meer CA, Devilee P, Cornelisse CJ, Niermeijer MF, and other members of the Rotterdam/Leiden Genetics Working Group. Presymptomatic testing for BRCA1 and BRCA2: how distressing are the pre-test weeks? J Med Genet 1999;36:906-913.

21. Cull A, Anderson EDC, Campbell S, Mackay J, Smyth E, Steel M. The impact of genetic counselling about breast cancer risk on women's risk perceptions and levels of distress. Br J Cancer 1999;79:501-508.

22. Watson M, Lloyd S, Davidson J, Meyer L, Eeles R, Ebbs S, Murday V. The impact of genetic counselling on risk perception and mental health in women with a family history of breast cancer. Br J Cancer 1999;79:868-874.

23. Watson M, Lloyd SM, Eeles R, Ponder B, Easton D, Seal S, Averill D, Daly P, Ormiston W, Murday V. Psychological impact of testing (by linkage) for the BRCA1 breast cancer gene: an investigation of two families in the research centre. Psychooncology 1996;5:233-239.

24. Lerman C, Marshall J, Audrain J, Gomez-Caminero A. Genetic testing for colon cancer susceptibility: anticipated reactions of patients and challenges to providers. Int J Cancer 1996;69:58-61. 